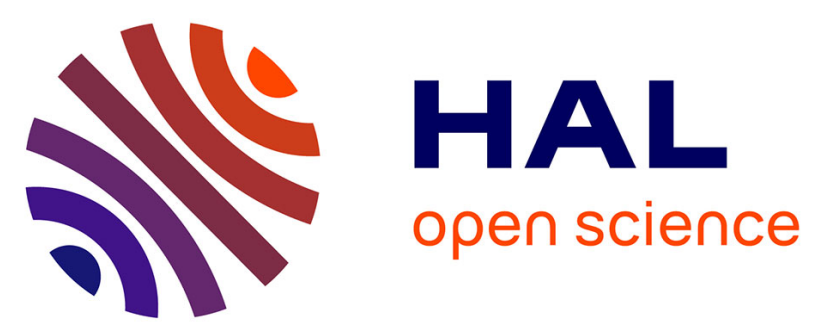

\title{
Exposures of zebrafish through diet to three environmentally relevant mixtures of PAHs produce behavioral disruptions in unexposed F1 and F2 descendant.
}

\author{
Caroline Vignet, Lucette Joassard, Laura Lyphout, Tiphaine Guionnet, \\ Manon Goubeau, Karyn Le Menach, François Brion, Olivier Kah, Bon-Chu \\ Chung, Hélène Budzinski, et al.
}

\section{- To cite this version:}

Caroline Vignet, Lucette Joassard, Laura Lyphout, Tiphaine Guionnet, Manon Goubeau, et al.. Exposures of zebrafish through diet to three environmentally relevant mixtures of PAHs produce behavioral disruptions in unexposed F1 and F2 descendant.. Environmental Science and Pollution Research, 2015, 22 (21), pp.16371-16383. 10.1007/s11356-015-4157-8 . hal-01121865

HAL Id: hal-01121865

https://hal-univ-rennes1.archives-ouvertes.fr/hal-01121865

Submitted on 20 May 2015

HAL is a multi-disciplinary open access archive for the deposit and dissemination of scientific research documents, whether they are published or not. The documents may come from teaching and research institutions in France or abroad, or from public or private research centers.
L'archive ouverte pluridisciplinaire HAL, est destinée au dépôt et à la diffusion de documents scientifiques de niveau recherche, publiés ou non, émanant des établissements d'enseignement et de recherche français ou étrangers, des laboratoires publics ou privés. 
Exposures of zebrafish through diet to three environmentally relevant mixtures of PAHs produce behavioral disruptions in unexposed F1 and F2 descendant.

Caroline Vignet $^{\mathrm{a}}$, Lucette Joassard ${ }^{\mathrm{b}}$, Laura Lyphout ${ }^{\mathrm{b}}$, Tiphaine Guionnet ${ }^{\mathrm{b}}$, Manon Goubeau ${ }^{\mathrm{a}}$, Karyn Le Menach ${ }^{\mathrm{c}}$, François Brion ${ }^{\mathrm{d}}$, Olivier Kah ${ }^{\mathrm{e}}$, Bon-Chu Chung ${ }^{\mathrm{f}}$, Hélène Budzinski ${ }^{\mathrm{c}}$, Marie-Laure Bégout ${ }^{\mathrm{b}}$, Xavier Cousin ${ }^{\mathrm{a}, \mathrm{g}^{*}}$

a Ifremer, Ecotoxicology Laboratory, Place Gaby Coll, BP7, 17137 L'Houmeau, France

b Ifremer, Fisheries laboratory, Place Gaby Coll, BP7, 17137 L'Houmeau, France

c University of Bordeaux 1, EPOC, UMR CNRS 5805, 33405 Talence, France

d Unité d'Ecotoxicologie in vitro et in vivo, Direction des Risques Chroniques, INERIS, 60550 Verneuil-en-Halatte, France

e Université de Rennes 1, Institut de Recherche Santé Environnement \& Travail (IRSET), INSERM U1085, BIOSIT, Campus de Beaulieu, 35000 Rennes France

f Taiwan Institute of Molecular Biology, Academia Sinica, Taipei, Taiwan

g INRA LPGP, Campus de Beaulieu, 35042 Rennes, France

* Corresponding author: Xavier Cousin - xavier.cousin@ifremer.fr

Tel +33546500621- Fax +33546500650 


\begin{abstract}
The release of polycyclic aromatic hydrocarbons (PAHs) into the environment has increased very substantially over the last decades. PAHs are hydrophobic molecules which can accumulate in high concentrations in sediments acting then as major secondary sources. Fish contamination can occur through contact or residence nearby sediments or though dietary exposure. In this study we analyzed certain physiological traits in unexposed fish (F1) issued from parents (F0) exposed through diet to three PAH mixtures at similar and environmentally relevant concentrations but differing in their compositions. For each mixture, no morphological differences were observed between concentrations. An increase in locomotor activity was observed in larvae issued from fish exposed to the highest concentration of a pyrolytic (PY) mixture. On the contrary, a decrease in locomotor activity was observed in larvae issued from Heavy Oil mixture (HO). In the case of the third mixture, Light Oil (LO), a reduction of the diurnal activity was observed during the set-up of larval activity. Behavioral disruptions persisted in F1-PY juveniles and in their offspring (F2). Endocrine disruption was analyzed using cyp19alb:GFP transgenic line and revealed disruptions in PY and LO offspring. Since no PAHs metabolites were dosed in larvae, these findings suggest possible underlying mechanisms such as altered parental signaling molecule and/or hormone transferred in the gametes eventually leading to early imprinting. Taken together, these results indicate that physiological disruptions are observed in offspring of fish exposed to PAH mixtures through diet.
\end{abstract}

Keywords: Danio rerio; polycyclic aromatic hydrocarbon; offspring; transgenerational effect; heavy oil; light crude oil; locomotor activity; photomotor response; anxiety-like behavior 


\section{Introduction}

Xenobiotics are increasingly emitted in the environment as a consequence of human activities. Among xenobiotics, a group of compounds, the persistent organic pollutants (POPs), share common characteristics: they are persistent in the environment, have lipophilic properties and high chemical stability, which confer them a strong capacity for bioaccumulation. As aquatic compartments, including sediments, often constitute an ultimate reservoir for these compounds, fish could be exposed at various life stages to POPs. Besides such direct exposure, POPs can be transmitted from parents to offspring, through blood during gestation and later in milk and induce physiological effects in the post-natal period for mammals (Crépeaux et al. 2012, 2013, Palanza et al. 2008, Wormley et al. 2004). For egg-laying species, embryonic exposure occurs mainly through yolk (e.g. for PCBs see (Bodiguel et al. 2009, Daouk et al. 2011, Ottinger et al. 2013). In addition to this indirect parental exposure route, physiological disruption in parents can also have consequences in offspring such as the alteration of signaling molecule and/or hormonal transfer: for example the transmission of elevated cortisol levels in fish eggs after parental stress experience has been shown to have physiological and behavioral consequences in juveniles (Auperin \& Geslin 2008, McCormick et al. 1998).

Further, there is a growing body of evidence that POPs can act as neurotoxicant especially in the case of early exposure (Ottinger et al. 2013, Scott \& Sloman 2004). This has been demonstrated in various animal species and there are strong correlations in humans between concentration of some POPs, especially in cord blood and latter cognition deficiencies or behavioral disruptions (Edwards et al. 2010, Jedrychowski et al. 2003, Letcher et al. 2010, Perera et al. 2012, Sagiv et al. 2010, Stewart et al. 2000, Tang et al. 2008).

Among POPs, polycyclic aromatic hydrocarbons (PAHs) constitute a wide family of compounds formed by the association of several aromatic rings. In addition, there are also PAHs derivatives substituted with alkyl groups, nitrogen, sulfur or oxygen. PAHs and their derivatives are produced during organic matter combustion (pyrolytic PAHs) or are present in oils (petrogenic PAHs). In all cases, PAHs are present as complex mixtures including a large number of PAHs and derivatives. PAH mixtures composition differs depending on their origin. Pyrolytic mixtures are characterized by high proportions of heavy PAHs such as 
benzo[a]pyrene $(\mathrm{BaP})$ and few alkylated PAHs while petrogenic mixtures contain less heavy PAHs but more light ones and higher proportions of alkylated PAHs (Benlahcen et al. 1997, Budzinski et al. 1997, Latimer \& Zheng 2003, Neff 1979, Yunker et al. 2002). PAHs release into the environment has increased over the last decades (Eisler 1987, Shen et al. 2013, Zhang $\&$ Tao 2009). Monitoring networks have documented PAH concentrations of up to $50 \mu \mathrm{g} . \mathrm{g}^{-1}$ dry weight $(\mathrm{dw})$ in sediment from various affected aquatic ecosystems although the concentrations in highly contaminated areas is more commonly in the $10 \mu \mathrm{g} \cdot \mathrm{g}^{-1}$ range (Baumard et al. 1998, Benlahcen et al. 1997, Cachot et al. 2006, Johnson et al. 2007, Varanasi et al. 1993, Yanagida et al. 2012). The concentration of PAH in the biota varies depending on the surrounding concentration and trophic level. For example, the total concentration of 16 PAHs used as indicators by the US Environmental Protection Agency (US-EPA) in the copepod Eurytemora affinis in the Seine Estuary is in the $0.2-3.9 \mu \mathrm{g}^{-g^{-1}} \mathrm{dw}$ range (Cailleaud et al. 2007) and in mussels it can be as high as $1.6 \mu \mathrm{g} . \mathrm{g}^{-1} \mathrm{dw}$ (Le Goff et al. 2006). In the case of acute accidental exposure, the concentration in mussels can be even higher, for example $3 \mu \mathrm{g} \cdot \mathrm{g}^{-1} \mathrm{dw}$ after the Erika oil spill (Jeanneret et al. 2002) and $14.4 \mu \mathrm{g} \cdot \mathrm{g}^{-1} \mathrm{dw}$ after Exxon Valdez oil spill (Payne et al. 2008). PAHs bioaccumulate in parts of the lower levels of the food chain, in which organisms have poor PAH metabolisation activities; consequently, food is an important exposure route. This has been demonstrated by the high concentrations of PAHs found in the stomachs of fish caught in contaminated areas (Johnson et al. 2007, Varanasi et al. 1993, Yanagida et al. 2012).

Few studies have described the behavioral disruptions consecutive to an exposure to PAHs in fish. In most cases, exposure have been performed using waterborne exposure of juveniles to unique compounds (Almeida et al. 2012, Correia et al. 2007, Goncalves et al. 2008, Gravato \& Guilhermino 2009, Oliveira et al. 2012). In addition, one study has also described additive effects when using a mixture of three PAHs (Goncalves et al. 2008). The general conclusion of these studies is that PAHs produced lethargy revealed by a decrease of exposed fish swimming ability. More recently studies have reported behavioral disruption in medaka and zebrafish exposed to PAHs spiked sediment at embryo and larvae stages. Behavioral disruptions were observed either in larvae only (Le Bihanic et al. 2014a) or in larvae, juveniles and adults (Vignet et al. 2014a). Finally, in another study, fish were continuously exposed through diet to three mixtures of PAHs starting at the first meal (5 days post fertilization; dpf). In this study several behavioral disruptions were observed indicative of the induction of an anxiety-like syndrome (Vignet et al. 2014b). 
Besides such direct consequences of exposures through water, sediment or food, the question of the consequences in fish in the next generation is of utmost importance particularly when building on current mammalian literature underlining several neurotoxicological defects due to maternal exposure to PAHs (Crépeaux et al. 2012, 2013). Several mechanisms may be envisioned including a transfer of PAHs and their metabolites to eggs which can result in a very early exposure of developing embryos and/or transmission of biased signaling molecule such as steroid hormones as cited above, resulting in a degraded ovocytes quality and finally an epigenetic imprinting.

Mechanisms underlying behavioral disruptions after PAHs exposure remain generally unknown. Several pathways have been proposed including disruption in cortisol, neurotransmitters and estrogen pathways. The later hypothesis of estrogen disruption is of particular interest if we consider the fact that PAHs are suspected to disrupt endocrine regulation and it is now documented in different taxa that early estrogenic imprinting drives several organ development, gender-specific brain development and associated behaviors (Ottinger et al. 2013, Ottinger et al. 2009, Panzica et al. 2007, Stocco 2012).

In the present study, we have analyzed behavioral responses of the offspring of dietary exposed fish. Founding generations (F0) have been exposed through diet to three complex mixtures of PAHs representative of environmental situations: a pyrolitic mixture (PY) and two petrogenic mixtures (Vignet et al. 2014c). The behavior of their offspring (F1) was analyzed at larval stage. Behavior of F1-PY has also been analyzed in 2 months old juveniles. The possible endocrine disruption effects of PAHs were explored by measuring the brain estrogenic activity using transgenic line expressing GFP under the control of brain aromatase (cyp19alb:GFP). In addition, behavior of F2-PY larvae has also been monitored.

\section{Material and Methods}

This study was conducted under the approval of the Animal Care Committee of France, under the official licence of M.-L. Bégout (17-010).

\section{Fish rearing ad offspring production}

We used the common laboratory TU strain (ZFIN ID: ZDBGENO-990623-3), which was established in the 90's in Tubingen and in our platform (PEP - http://wwz.ifremer.fr/pep) 6 years ago as large batches of individuals originating from the Amagen platform (Gif/Yvette, France) and the Pasteur Institute fish facility (Paris, France). For the assessment of brain glial 
cell aromatase expression we used a transgenic line cyp19alb:GFP (Tong et al. 2009). Both lines were contaminated through diet following the protocol described in (Vignet et al. 2014c) with three PAHs mixtures and reared until adulthood for offspring production. We used i) a pyrolytic fraction (PY) extracted from sediments collected in the polluted site of the Seine Estuary (Oissel, France) and ii) two petrogenic fractions obtained from Erika fuel (heavy oil; HO) and Arabian Light crude oil (LO). PAHs extractions were performed as previously described (Cachot et al. 2006). Zebrafish were exposed from their first meal (at $5 \mathrm{dpf}$ ) onward and exposed using spiked size-graded food pellets (INICIO Plus 0.5, Biomar, France). Three concentrations, $0.3 \mathrm{X}, 1 \mathrm{X}$ and $3 \mathrm{X}$ were used with the $1 \mathrm{X}$ concentration corresponding to the $\Sigma\left[16 \mathrm{EPA}\right.$ PAH] at $5 \mu \mathrm{g} \cdot \mathrm{g}^{-1} \mathrm{dw}$ food, representative of the concentrations found in mollusks in the Seine Estuary. Diets are named after the origin of the fraction and its concentration: $1 \mathrm{X}$ pyrolytic fraction diet will be named: PY-1X. For each exposure, a fourth control treatment has been included corresponding to the plain food treated as spiked-food with dichloromethane which was used as carrier solvent for PAHs spiking. Control and exposed fish were maintained at $27^{\circ} \mathrm{C}$ in a controlled 14-h light/10-h dark (14:10) photoperiod and were fed twice a day with spiked diet between 9:00 and 9:30 in the morning and 16:30 and 17:30 in the afternoon and once with plain artemia nauplii (INVE AQUACULTURE nv, Dendermonde, Belgium) between 11:30 and 12:30.

When the onset of spawning was confirmed (4 month-old PY and HO, 5 month-old LO and 3 month-old fish for cyp19alb:GFP) eggs were obtained by random pairwise or group mating. Eggs were collected in the morning and the fertilization rate assessed within $2 \mathrm{~h}$ of collection. At the same time, spawns were sorted to remove feces, and dead or unfertilized embryos. Developing embryos and larvae were maintained in $\mathrm{E} 3$ medium $(5 \mathrm{mM} \mathrm{NaCl}, 0.17 \mathrm{mM} \mathrm{KCl}$, $0.33 \mathrm{mM} \mathrm{CaCl} 2,0.33 \mathrm{mM} \mathrm{MgSO} 4)$ at $28^{\circ} \mathrm{C}$ in Petri dishes in an incubator with the same photoperiod as adults. After hatching, chorions were removed manually, usually at $3 \mathrm{dpf}$, and larvae were used for behavioral experiments.

For PY only, some larvae were also bred according to standard protocols (Nüsslein-Volhard \& Dahm 2002) and fed with artemias and size-graded plain pellets (INICIO Plus 0.5, Biomar, France) from 5 dpf onward until fish reached sexual maturity. F1-PY adult fish were then used to produce offspring (F2-PY) using the same procedure as described above.

\section{Behavioral experiments}

We used 4-7 days old F1 larvae issued from PY, LO and HO parents, 2 month old sex undifferentiated F1 fish issued from PY parents and 5 days old larvae (F2-PY) issued from 
F1-PY fish for behavioral tests. Tests were done in a dedicated room kept at $27^{\circ} \mathrm{C} \pm 1{ }^{\circ} \mathrm{C}$, with a 14:10 photoperiod synchronized with the rearing room so as to minimize unwanted correlated effects. Daylight started at 08:30 and there were no twilight transition periods. F0 exposures were performed successively for the three mixtures (Vignet et al. 2014c), the same applied for F1 production and behavioral assays. For all tests we tried as much as possible to evaluate an equal number of F1 larvae from parents exposed to all concentrations (Control, $0.3 \mathrm{X}, 1 \mathrm{X}$ and $3 \mathrm{X})$. In particular for assays involving 24-well plates we tried to have larvae from all F0 in the same plate to avoid any trial effect.

\section{Photomotor response (PMR) in F1 5 dpf larvae}

We monitored the photomotor response (Burgess \& Granato 2007, Emran et al. 2008) in 5 dpf larvae in a light/dark challenge, following a method slightly modified from that of Ali et al. (Ali et al. 2012) and described in details in Vignet et al. (Vignet et al. 2013). This method is used extensively in the behavioral profiling of zebrafish larvae exposed to diverse compounds for drug screening and to assess anxiety level in larvae.

At 17:00 the day before the challenge ( $4 \mathrm{dpf}$ ), single larvae were transferred to individual wells of a 24-well plate (Krystal 24, opaque wall and clear bottom micro-plate) where they were arranged in a mixed design and visually isolated from each other, the four corner wells were left empty because video acquisition suffered distortion. The 24-well plates were kept overnight in the breeding incubator. The following day, two hours before the challenge, well plate was transferred to the video acquisition room and placed on top of a size-matched infrared floor, which allowed the larvae to be filmed under both light and dark conditions (Vignet et al. 2013). After a 10-min acclimation period, the 15-min challenge included three 5-min periods: Light on-1 (70 1x.), Light off ( $<1$ lx.) and Light on-2. Challenges were conducted between 14:00 and 18:00, the most stable activity period in zebrafish larvae (MacPhail et al. 2009). Constant IR lighting was maintained during filming using a three-way switch. The apparatus was enclosed within a lightproof and temperature-controlled box. Locomotor activity was assessed as previously described (Vignet et al. 2013) as well as inner vs. outer area occupancy after (Schnorr et al. 2012). The dependent variables measured were distance travelled $(\mathrm{cm})$ and residence time in inner vs. outer areas (see figures 2 and 4 legends for treatment and number of larvae studied). 
This method was used to monitor the onset of the swimming activity as well as the expression of the circadian activity rhythm in larvae (Vignet et al. 2013). The same microplate preparation was done as above, except that single larvae were transferred at $3 \mathrm{dpf}$. The following day ( $4 \mathrm{dpf}), 2 \mathrm{~h}$ before the challenge, the well plate was transferred to the video acquisition room under the same conditions as described above. It is to note that larvae from different spawns were used for PMR and this test. The recording of the larval swimming activity started at 12:00 and continued for $72 \mathrm{~h}$. The dependent variable measured was the distance travelled $(\mathrm{cm})$, see legend of figure 3 for treatment and number of larvae studied.

\section{Novel tank test}

In addition to providing information on the exploratory ability of the fish, the swimming characteristics recorded during exploration are giving indications as to how fish cope with this novel environment. Indeed the use of the novel tank test as been validated to evaluate anxiety level by monitoring vertical position (Egan et al. 2009, Levin et al. 2007). Here the novel tank challenge was performed in 2-month old offspring issued from PY parents. After 2 hours of acclimatization in the room in $1 \mathrm{~L}$ aquarium, fish were transferred to a novel tank (trapezoid 1.5 L tank; Aquatic Habitats, Apopka, FL; sizes in cm: height $15.2 \times$ width 7.1 x length 27.9 at top and 22.5 at bottom) and filmed for 6 minutes in side view. Twelve fish were challenged per concentration. For space occupancy analysis, tanks were separated into two areas according to Egan et al. (2009): the top area including one half of the volume and the bottom area including the other half; the dependent variable measured was the time spent in each area (top, bottom; s) per minute, and for the all 6 min test duration, the total distance travelled $(\mathrm{cm})$ and the total time spent immobile (s).

\section{Behavioural data recording and analysis}

Videos for the PMR, the 72-h swimming activity setup and the novel tank test were recorded with an analogue camera ICD-48E (Ikegami) and 2.7-13.5 mm lens (Fujinon) linked to a PC with an acquisition card and Ethovision XT 8.5 software (Noldus, The Netherlands).

For all experiments, EthoVision XT software was used for track extraction and analysis. Data were acquired by EthoVision at 25 frames per second, and variables were nested for further treatments every 30-s in larvae during the PMR, every 30-min for the 72-h swimming activity setup and every one or six minutes in novel tank experiments with 2-month old juveniles. For assessments of the time spent immobile, we used the mobility detection function of EthoVision XT and we set the lower threshold for separating immobility from mobility at 
$20 \%$ (i.e. indicating that a change of no more than $20 \%$ in the pixels of a detected object between two consecutive samples would be considered to indicate immobility, see EthoVision XT Reference Manual).

\section{Aromatase expression in vivo}

F1 embryos exposed to the ethinyl estradiol (EE2) were issued from cyp19alb:GFP transgenic F0 (Tong et al. 2009) exposed through diet to the 3 same PAH mixtures. At 4-5 hours post fertilization, 30 fertilized eggs were placed in beakers with $30 \mathrm{ml}$ of E3, and EE2 was added to final concentrations of $0.005,0.017,0.05$ and $0.17 \mathrm{nM}$. Between 1 and 5 replicates were done depending on fractions and concentrations due to eggs availability (see supp. Table 1 for details). The beakers were incubated at $28^{\circ} \mathrm{C}$ with the same photoperiod as adults. On day 6 after fertilization, larvae were anaesthetized with benzocaine (final concentration $50 \mathrm{mg} . \mathrm{L}^{-1}$ ) and were placed in methylcellulose at $3 \%$ under a fluorescence microscope (Brion et al. 2012). All the larvae were observed in dorsal view and each was photographed using an Olympus BX41 microscope and a fluorescence source (XCite series 120 Q, SCOP PRO, Itteville, France) equipped with a DMK 31AU03 monochrome camera and IC-Capture software (The Imaging Sources, Germany). All photographs were taken using the same parameters: only the head was photographed using X10 objective, with a $774 \mathrm{~ms}$ exposure time and maximal intensity (gain at 500). Fluorescence quantification was performed using the ImageJ software. For each picture taken (61 to 384 larvae depending on fractions and concentrations, see supplementary table 1), the integrated density was measured, i.e. the sum of the gray-values of all the pixels within the region of interest defined as in (Brion et al. 2012).

\section{Statistical analysis}

Statistical analyses were performed with Statistica 9.0 (Statsoft, Tulsa, OK, USA) software. GLM was applied in each case. In all tests, within each fraction (PY, HO or LO), concentration (control, $0.3 \mathrm{X}, 1 \mathrm{X}$ and $3 \mathrm{X}$ ) and periods (light/day vs. dark/night in larvae PMR and 72-h swimming activity setup tests; Light on-1, Light-off, Light on-2 during the PMR test; min-1 to 6 in novel tank test) or areas (in novel tank test) were tested as fixed factor and fish and session as random factor. Interaction between concentration and period was also analyzed. Total distance travelled and time spent immobile in novel tank test were compared with only concentrations as fixed factor and fish and session as random factor. Fluorescence quantified by the integrated density was also analyzed using GLM. Within each fraction, 
integrated density was compared with two fixed factors (PAHs concentration (as above) and EE2 concentrations $(0.005,0.017,0.05$ and $0.17 \mathrm{nM})$ and, fish and calibration range (only for PY) as random factors. All statistical analyses were carried out at a 95\% level of significance and only the fixed factor and the interaction between them are presented in the text. Post-hoc test were performed with Newman-Keuls in each case. The results reported in text and all figures are means \pm SEM.

\section{Results}

Results obtained for the F0 exposure have been described in previous articles (Vignet et al. 2014b, Vignet et al. 2014c) and will not be detailed here. However, some information is important for the understanding of this article and will be briefly recalled here. PAH mixtures were different in terms of individual PAHs and alkylated PAHs proportions but total PAHs concentrations were similar in the 4.7-6.7 $\mu \mathrm{g} \cdot \mathrm{g}^{-1} \mathrm{dw}$ range for the intermediate concentration (1X) and PAH metabolites quantification revealed an effective exposure of F0. Several physiological effects were observed including the alteration of F0 growth (Vignet et al. 2014c) and behavioural disruptions (Vignet et al. 2014b) and depending on the mixture used, with an increasing severity as follow: $\mathrm{PY}<\mathrm{LO}<\mathrm{HO}$. Another effect was a disruption of reproduction (Vignet 2014). This was particularly severe for PY-3X, and $1 X$ and $3 X$ concentrations for LO and $\mathrm{HO}$ mixtures resulting in very few or no eggs produced. A direct consequence of these disruptions is that results reported here mainly deal with PY exposure (all concentrations), LO-0.3X and HO-0.3X. The second consequence is that only F1-PY fish were bred to adulthood and only F1-PY offspring (F2-PY) were produced.

\section{Photomotor response in F1 5 dpf larvae}

The PMR of Control larvae followed the expected pattern which was a clear increase $(\sim 60 \%)$ of distance travelled during the Light off period compared to the previous period (Light on-1). Activity during the following light on period (Light on-2) then decreased to reach levels observed during Light on-1 period (Fig. 1).

In the case of the PY mixture (Fig. 1a, b), F1 larvae distance travelled was significantly modified. This was revealed by significant period $(\mathrm{F}=37.02 ; \mathrm{p}<0.001)$ and concentrations $(\mathrm{F}=5.05 ; \mathrm{p}=0.002)$ effects but no significant interaction was observed. Indeed, whereas larvae issued from PY-0.3X and PY-1X parents displayed the same PMR as larvae issued from Control parents, larvae issued from PY-3X parents had a higher level of activity whatever the 
light period $(\mathrm{p}<0.001)$ and showed no significant activity increase during Light off when compared with Light on-1 period $(\mathrm{p}=0.279)$.

For larvae issued from HO parents, there was a significant difference between periods for distance travelled $(\mathrm{F}=73.97$, $\mathrm{p}<0.001$; Fig. 1c) and a significant difference was also observed between concentrations $(\mathrm{F}=40.56 ; \mathrm{p}<0.001)$ but no significant interaction was measured. Activity of larvae issued from HO-0.3X parents displayed the usual pattern however, it was significantly reduced during both light on periods compared to larvae issued from Control parents $(p<0,001)$ as well as during the light off period ( $<<0.001$; Fig. 1d).

In the case of larvae issued from LO parents (Fig. 1e, f), a difference between periods was observed for distance travelled $(\mathrm{F}=20.79 ; \mathrm{p}<0.001)$ but no significant difference was observed between concentrations $(\mathrm{F}=1.72, \mathrm{p}=0.19$; Fig. 1f) and no interaction was measured.

In addition to locomotion analyzed in whole wells, the time spent in inner and outer areas of each well, as well as the activity within each area was monitored. Whatever the mixtures and the concentrations, no difference between inner vs. outer area occupancy or activity was observed (data not shown).

\section{Seventy-two-hour swimming activity setup in F1 larvae}

The spontaneous activity of larvae was monitored during 72 hours starting from $4 \mathrm{dpf}$ and included day and night periods using different larvae from different spawns than the ones used for PMR assessment. Because of the very low spawning of HO this was performed only for F1-PY and F1-LO. During day periods, distance travelled by larvae issued from Control parents increased progressively during day 4 to reach a maximum during day 5 and then decreased to a low level during day 6. Conversely, during night periods, activity was strongly reduced.

Circadian spontaneous swimming activity of larvae issued from PY parents showed the same general pattern whatever the concentration to which parents were exposed (i.e. no concentration effect was shown, $\mathrm{F}=0.73$; $\mathrm{p}=0.53$; Fig. 2a) but significant differences between periods $(\mathrm{F}=365.11 ; \mathrm{p}<0.001)$ and significant interaction between period and concentration were noteworthy $(\mathrm{F}=3.89 ; \mathrm{p}=0.011)$ with in particular the decrease in the activity of larvae issued from PY-0.3X during all day periods. This resulted in a significant decrease of total distance travelled during diurnal periods ( $\mathrm{p}=0.003$; Fig. 2b). On the contrary, activity of larvae issued from PY-3X parents increased especially during day periods 5 to $7 \mathrm{dpf}$ (Fig. 2a). This resulted in a significant increase of total distance travelled during diurnal periods 
( $<<0.001$; Fig. 2b). The diurnal activity of PY-1X offspring was intermediate between PY$0.3 \mathrm{X}$ and PY-3X and at the level of Control offspring. No difference was observed between concentrations for nocturnal periods (Fig. 2b).

Circadian spontaneous swimming activity of larvae issued from LO parents presented the above described pattern obtained for larvae issued from Control parents. Whatever the concentration a clear higher diurnal activity was observed with a significant difference between periods $(F=102.52 ; p<0.001$; Fig. $2 c)$, between concentration $(F=21.00 ; p<0.001$; Fig. 2c) and a significant interaction between concentrations and periods $(F=4.21 ; p=0.017)$. Diurnal swimming activity of larvae issued from LO-0.3X $(p<0.001)$ and LO-1X $(p<0.001)$ parents was significantly reduced compared to offspring of Control parents.

\section{Novel tank test - 2 month old F1-PY}

At the beginning of the test, juveniles spent most of the time in the bottom area, and the time spent in top area increased over test duration $(\mathrm{F}=12.89 ; \mathrm{p}<0.001$; Fig. 3a) and was different between concentrations $(\mathrm{F}=5.39 ; \mathrm{p}=0.001)$ with no significant interaction. Post-hoc tests revealed that larvae issued from PY-3X parents spent more time in top area compared to larvae issued from Control parents $(\mathrm{p}=0.008)$. Total time spent in top zone (during the whole test duration) was however not different between concentrations ( $F=1.32 ; \mathrm{p}=0.28$; Fig. 3b). Distance travelled and time spent immobile during the whole test duration did not significantly differ between concentrations $(\mathrm{F}=0.21, \mathrm{p}=0.88 ; \mathrm{F}=0.83, \mathrm{p}=0.48$ respectively; Fig. 3c-d). Analysis of juveniles morphology revealed no differences according to parents exposure for body length $(1.97 \pm 0.04 \mathrm{~cm} ; \mathrm{F}=0.39 ; \mathrm{p}=0.76)$ or body mass $(128.7 \pm 9.3 \mathrm{mg}$; $\mathrm{F}=0.29 ; \mathrm{p}=0.84)$.

\section{Photomotor response in F2 5 dpf larvae}

The PMR of F2 larvae issued from Control parents followed the same pattern as described for F1 larvae (Fig. 4a, b) with a significant difference between periods $(F=61.32 ; p<0.001)$. A significant difference was also observed between concentrations to which F0 were exposed $(\mathrm{F}=5.79 ; \mathrm{p}<0.001)$ but no significant interaction was measured. Distance travelled by F2-PY1X larvae was lower than that of F2-Control larvae during both light on periods $(\mathrm{p}<0.001$ for L1 and $\mathrm{p}=0.047$ for L2; Fig. 4b).

\section{Endocrine disruption}


To evaluate possible endocrine disruption in larvae brain which may be explicative of F1 larval phenotypes, a transgenic line was used expressing GFP under the control of brain aromatase (cyp19a1b) promoter (Tong et al. 2009). F0 transgenic fish were exposed as described before for TU line and offspring monitored for GFP expression. Basal activity (in the absence of EE2 stimulation) was similar between all tested offspring compared to their respective control (inserts in Fig. 5). Incubation of embryos and larvae in EE2 increased GFP expression in a EE2 dose dependent manner for all diets (PY; $\mathrm{F}=175.27$; $<<0.001$; HO; $\mathrm{F}=8.87 ; \mathrm{p}<0.001$ and LO; $\mathrm{F}=23.09 ; \mathrm{p}<0.001)$ but no significant effect of PAHs concentration was measured and no significant interaction either. Post-hoc tests revealed a significant reduction of GFP induction by EE2 for PY offspring (concentration $0.3 \mathrm{X}(\mathrm{p}=0.004)$; $1 \mathrm{X}$ $(\mathrm{p}=0.011)$ and $3 \mathrm{X}(\mathrm{p}=0.023))$ for a EE2 concentration of $0.05 \mathrm{nM}$. This inhibition was $43 \%$ for PY-0.3X offspring and 33\% for PY-1X and PY-3X offspring. At the highest concentration used for EE2 (0.17 nM) an inhibition was only observed for PY-0.3X offspring (-37\%; Fig. 5a). A strong reduction of GFP expression was observed in the brain of HO-0.3X larvae ($74 \%$ ) for an EE2 concentration of $0.05 \mathrm{nM}$ but because of a high variation in Control larvae this was not significant (Fig. 5b). In the case of LO offspring, none of the LO-0.3X offspring survived to an EE2 exposure at a concentration above $0.017 \mathrm{nM}$. At lower concentrations, no difference was observed between Control and LO-0.3X offspring (Fig. 5c).

\section{Discussion}

The three diets used for parents (F0) exposure had similar overall PAHs concentration but differed significantly in their composition, according to fractions used for spiking. PY was characterized by a high level of heavy PAHs and a very low level of alkylated PAHs. LO contained a high level of alkylated PAHs and a low level of heavy PAHs while HO was intermediate for both groups of PAHs (Vignet et al. 2014c). Exposures caused, in F0, growth disruption (Vignet et al. 2014c) and altered behavioral performances (Vignet et al. 2014b). However phenotypes severity differed with respect to the mixture with an increasing toxicity as follow: PY < LO < HO. This ranking was also observed when comparing survival and tumorigenesis (Larcher et al. 2014). In this study, we evaluated the behavior of offspring of fish exposed to those three PAH mixtures. However, as reproduction was also significantly disrupted, very few offspring (F1) were obtained from PY-3X as well as LO and HO exposed fish (Vignet 2014). As a consequence only larval behavior was evaluated for F1-LO and F1$\mathrm{HO}$ for available concentrations. Further, because analysis in F0 suggested an increase in fish 
anxiety level (Vignet et al. 2014b), the study of F1 behavior focused on this particular angle in particular for F1-PY at larval and juvenile stages.

F1 larvae morphology was assessed at $96 \mathrm{hpf}$ and neither morphological defects nor body length differences were observed whatever the diet parents were exposed to (Lucas et al. 2014, Perrichon 2014). The only exception was for PY-0.3X F1 which presented a very weak $(+1.4 \%)$ increase of body length (Lucas et al. 2014). Larval heart rate was also monitored revealing no differences for F1 from LO fish (Perrichon 2014). In the case of F1 from PY fish, results are contradictory since some authors indicated a tachycardia for PY-1X F1 (Lucas et al. 2014) while a bradycardia is reported for PY-0.3X, PY-1X and PY-3X (Perrichon 2014). These contradictions are puzzling and do not allow to conclude for a functional effect. Further, monitoring of PY-F1 aerobic metabolism revealed no differences with control F1 (Lucas et al. 2014). No such data is available for HO or LO F1. Taken altogether, these results suggest that neither morphological nor metabolic disruption could be responsible for the behavioral phenotypes alteration observed in F1.

In F1, two assays were used to evaluate anxiety and/or activity level in $5 \mathrm{dpf}$ larvae and to evaluate the set-up of locomotor activity from 4 to $7 \mathrm{dpf}$. In the case of PY, an elevated activity was observed in the PMR challenge only for F1-PY-3X and during all three phases of the challenge while other F1-PY had the same activity level as F1-Control. An increase in the dark phase during PMR may be indicative of a higher anxiety level (Steenbergen et al. 2011). However, this should also be accompanied by an avoidance of the center area of wells (Schnorr et al. 2012, Steenbergen et al. 2011) which was not observed here. In addition, the locomotor activity of F1-PY-3X larvae was increased irrespective of the period (light or dark). Altogether, this suggests that hyperactivity should be a favored hypothesis to explain behavioral responses of F1-PY-3X. This is supported by the analysis of locomotory activity set-up which revealed an overall increase of F1-PY-3X activity during diurnal periods compared to F1-Control. This is particularly obvious during day 5 which corresponded to the day of highest larval activity (Vignet et al. 2013). In the case of PY-0.3X and $1 X$ offspring, no modification of PMR was observed. Locomotory activity set-up was differentially modified according to PY concentration: F1-PY-0.3X had a lower diurnal activity compared to Control larvae especially during days 5 and 6 , and F1-PY-1X had an intermediate diurnal activity between $0.3 \mathrm{X}$ and $3 \mathrm{X}$ larvae therefore not differing from Control larvae.

As said earlier, in the case of offspring of petrogenic exposed F0, only partial results were obtained. For HO mixture, only F1-HO-0.3X were obtained and tested only for their PMR. 
These larvae displayed an overall reduction of their activity, suggesting lethargic effects inducing general hypoactivity. PMR of F1-LO-0.3X did not differ from the one of Control larvae. But, when assessed during 72h, locomotory activity in F1-LO-0.3X and F1-LO-1X displayed an overall significant decrease in their diurnal activity. Since it was not possible to perform all assays with offspring from all concentrations, it is difficult to go further in the discussion on the behavior of $\mathrm{HO}$ and LO offspring apart from noticing an either overall (HO) or a diurnal only (LO) lethargic effect.

Such differences in severity and/or nature of disruptions according to the mixtures have also been shown in zebrafish F0 after exposure through diet (Larcher et al. 2014, Vignet et al. 2014b, Vignet et al. 2014c) as well as in medaka after sediment-contact exposure (Le Bihanic et al. 2014a, Le Bihanic et al. 2014b). The authors suggested that these differences likely reflected composition differences between mixtures and the triggering of (at least partially) different mechanisms. It is therefore logical that disruptions identified in F1 were also different.

Because of the low number of HO and LO offspring, only F1-PY were bred to adulthood and therefore assessed at later stage. The behavior of F1-PY juveniles was then evaluated at $2 \mathrm{mpf}$ using the novel-tank assay. This assay has been described as a good and simple indicator of anxiety level since at introduction in this new environment fish dive to the bottom of the tank and progressively start to explore the upper area (Egan et al. 2009, Levin et al. 2007, Sackerman et al. 2010). The proportion of time spent in the upper area is increased by anxiolytic drugs and decreased by anxiogenic ones (Egan et al. 2009, Levin et al. 2007). Offspring of PY fish displayed the expected pattern with a progressive increase of time spent in the upper area. The only difference observed is an overall higher proportion of time spent in this upper area for F1-PY-3X. Since there was no modification of locomotor activity (distance travelled), this relaxed home based behavior could be indicative of a lower anxiety level compared to Control juveniles. This hypothesis would fit well with the lowering (however non-significant statistically) of the time spent immobile as described previously (Cachat et al. 2010). Here again no morphological difference was observed between offspring whatever the PY concentrations.

Taken altogether, these results suggest that exposure of parents to PAH mixtures can lead to behavioral disruptions in their offspring at larval stage and in the case of PY mixture, it appears that after hyperactivity at larval stage, further disruptions can also be observed later in juveniles. Further analyses should be conducted to explore early brain imprinting and evaluate 
the potential relationship between PAHs and the concentration of neurotransmitters (such as dopamine and serotonin) which are also regulating behavioral repertoire as shown in trout after PAHs injection (Gesto et al. 2008, 2009) or in rats after PCBs perinatal exposure (Boix et al. 2011).

Disruption of fish behavior after exposure to PAHs has already been demonstrated. Indeed, juvenile fish exposed to individual or a simple mixture of PAHs have a decreased locomotor activity compared to Control fish (Almeida et al. 2012, Correia et al. 2007, Goncalves et al. 2008, Gravato \& Guilhermino 2009, Oliveira et al. 2012). Authors concluded to a lethargic effect of PAHs exposure. More recently a long-term exposure to three PAH mixtures from the first meal until behavioral assessment (the parents (F0) of fish described in the present article) produced anxiety-like disruptions (Vignet et al. 2014b). Two other studies recently published reported behavioral disruption upon embryo-larval exposure (one in medaka and one in zebrafish). In the first one, medaka embryos have been exposed using sediment spiked with the same three fractions as the ones used in the present article (PY, HO and LO) and larval behavior was monitored at 4 days post-hatching using a similar PMR procedure (Le Bihanic et al. 2014a) except for LO-1X, LO-3X, HO-1X and HO-3X larvae which were not tested due to poor or no survival. The classical PMR was observed for all concentrations and fractions however larvae presented several behavioral differences compared to the Control such as an increase of the distance travelled during the acclimation period (PY-3X, HO-0.3X and LO$0.3 \mathrm{X}$ ), during the following light on period (HO-0.3X and LO-0.3X) as well as an increase in the sum of high mobility periods during dark and light periods (PY-3X) or dark periods only (HO-0.3X and LO-0.3X) (Le Bihanic et al. 2014a). These results are indicative of an induction of activity in larvae after embryonic exposure to PAHs. In this study no analysis were performed at later stages preventing the identification of long lasting behavioral disruptions. In the second study, we have demonstrated that early exposure of zebrafish embryo (during the first 4 days) to sediment spiked with a mixture of three individual PAHs produced behavioral disruptions at later stages, in juveniles and adults suggesting lethargic or anxiety-related behavior (Vignet et al. 2014a) and this latter behavior was also identified in their offspring at larval stage.

When comparing perinatal (the above cited studies) and prenatal (the present study) exposures some differences are revealed. Here, in the case of prenatal exposure with different mixtures, larvae issued from PY-3X fish showed hyperactivity and lower anxiety levels. Such contrasted results cannot be directly compared since mixtures differed but they echo the 
findings of Crépeaux et al. (2012, 2013) who highlighted different consequences on adult male rats' behavior and regional brain metabolism depending on whether exposure to $16 \mathrm{PAH}$ mixture was exclusively prenatal or perinatal.

In the present case of F1 offspring of F0 exposed fish, behavioral disruptions may be due to the exposure of embryos and larvae to PAHs after maternal transfer to the egg since such transfer has been reported in birds (Pereira et al. 2009), fish (Monteverdi \& Giulio 2000, Tilghman Hall \& Oris 1991) and mollusks (Pelletier et al. 2000). However, no PAH metabolites have been detected in $5 \mathrm{dpf}$ F1 larvae. It is possible however that PAHs or their metabolites were present earlier and may have caused precocious disruption. However, it is noteworthy that Cypla enzymatic activity is debated in early zebrafish larvae since, while cypla expression is quickly activated by AhR agonists in larvae, Cypla activity seems to be not induced before $3 \mathrm{dph}$ (Mattingly \& Toscano 2001). Whatever, the absence of metabolites in 5 dpf larvae suggests a very low level of PAHs, if any transferred to eggs therefore behavioral disruptions cannot be attributed to a direct effect of PAHs. Alternatively, behavioral disruptions can also be due to several other non-exclusive events such as i) disruption of egg content in signaling molecules or other component in relation with endocrine disruption (ED) or ii) epigenetic imprinting of gametes which can deregulate embryonic development and/or later fish physiology. Further, some disruptions were also observed in F2-PY. this suggest that behavioral disruption can be transmitted to further generation. It is noteworthy that disruptions are different from those observed in F1-PY suggesting the involvement of different mechanisms. At this stage, it is not possible to say this is an epigenetically driven disruption since primordial germ cells involved in F2 production were present in F1 at embryonic stages and may have been directly exposed to the disrupting signal (Anway \& Skinner 2006).

Because some POPs act as endocrine disruptors and early endocrine disruption has been proposed to mediate some behavioral defects in fish, birds and mammals (Ottinger et al. 2013, Ottinger et al. 2009, Panzica et al. 2007, Reyhanian et al. 2011, Stocco 2012, Volkova et al. 2012), we evaluated potential early ED in F1 larvae. This was performed using in vivo assessment of brain aromatase (cyp19a1b) promoter activation upon EE2 exposure (Brion et al. 2012). In F1-PY larvae a significant reduction of cyp19alb activation by EE2 was observed whatever the PAH's concentration F0 were exposed to. In the case of F1-HO larvae no modification of cyp19alb inducibility was observed. Finally, exposures of F1-LO to EE2 lead to larval death for concentrations above $0.017 \mathrm{nM}$. These results suggest an endocrine disruption in F1-PY and F1-LO. They also suggest different disruptions between these two 
treatments. In the case of F1-PY, results suggest an inhibition of the response to EE2 exposure which may be reminiscent of what has been observed in waterborne exposure to TCDD alone or in combination with EE2 (Brion et al. 2012). In this experiment, TCDD alone did not modify GFP expression monitored using the same transgenic line. However, an exposure combining TCDD and EE2 led to a decreased induction of GFP when compared to EE2 alone. Since TCDD and heavy weight PAHs share common pathways such as aryl hydrocarbon receptor (AhR) (Billiard et al. 2002), it is possible to envision a similar mechanism of action in F1-PY larvae. In the case of F1-LO, it is likely that another mechanism is involved. In this respect, it is noteworthy that early exposure to ED compound can promote sensitization and therefore such exacerbated response to later exposure has been demonstrated, albeit on a different time scale with roach exposure to EE2 (Lange et al. 2009). So it is possible that F1LO larvae were sensitized to estrogen and that an additional exposure to EE2 led to larval death. The fact that differential EE2 responses were observed between F1-PY and F1-LO offspring is in agreement with the differential behavioral disruptions observed in larvae. This does not rule out other mechanism(s) such as differences in DNA methylation profile which can result in genes expression differences and ultimately, if transmitted to next generation, in epigenetic effects. Such transgenerational effects have been recently reported in zebrafish after pulse exposure of juveniles to an AhR inducer, dioxin (Baker et al. 2014). Recently, changes in DNA methylation and in genes expression have been reported in F0 zebrafish after exposure to two PAHs, benzo(a)pyrene and 7,12-dimethylbenz(a)anthracene (Corrales et al. 2014, Fang et al. 2013, Mirbahai et al. 2011). It is therefore possible that such mechanisms are involved in F1 and F2 phenotypes described here.

\section{Conclusion}

This work illustrates the fact that zebrafish is amenable to sophisticated analyses, here effects on F1 generation thanks to its short lifecycle, to evaluate aquatic toxicology. This work also demonstrates that physiological effects can be observed in offspring of fish exposed to PAHs which themselves were not directly exposed to this pollutant. We and others have already reported this in offspring of fish exposed to PCBs (Pean et al. 2013) and BDE-209 (He et al. 2011) but contrary to PCBs, PAHs and PBDE to a lesser extent, are readily metabolized in fish. In this respect PAHs metabolites were not detected in F1. It is thus possible that zebrafish, exposed to environmental PAHs mixtures through diet, could also serve as a model to improve the understanding of the mechanisms underlying the appearance of behavioral disorders through generations. Finally, from an ecological point of view, this indicates that 
detrimental behavioral disruptions (lower exploratory abilities, increase of predation risks) may possibly occur in fish offspring in places devoid of intrinsic pollution as a consequence of parent's exposure elsewhere in their dynamic habitat. Two more elements point to the potential detrimental effect of PAHs exposure: first, disruptions were also observed in F2 generation for PY mixture and second, concentrations used were in the range of those measured in the environment.

\section{Acknowledgements}

We thank Laura Frere, Cathy Haget and Didier Leguay, for their help. This study was supported financially by the ANR project ConPhyPoP (CES 09_002) and CPER A2E. This later project is co-financed by the European Union with the European fund of regional development. A doctoral grant was received from the Région Poitou-Charentes and from l'Institut Français de Recherche pour l'Exploitation de la Mer (C.V.). This work was part of the LABEX COTE cluster of excellence "Continental to coastal ecosystems".

\section{References}

Ali S, Champagne DL, Richardson MK (2012): Behavioral profiling of zebrafish embryos exposed to a panel of 60 water-soluble compounds. Behav Brain Res 228, 272-283

Almeida JR, Gravato C, Guilhermino L (2012): Challenges in assessing the toxic effects of polycyclic aromatic hydrocarbons to marine organisms: a case study on the acute toxicity of pyrene to the European seabass (Dicentrarchus labrax L.). Chemosphere 86, 926-937

Anway MD, Skinner MK (2006): Epigenetic transgenerational actions of endocrine disruptors. Endocrinology 147, S43-9

Auperin B, Geslin M (2008): Plasma cortisol response to stress in juvenile rainbow trout is influenced by their life history during early development and by egg cortisol content. Gen Comp Endocrinol 158, 234-9

Baker TR, Peterson RE, Heideman W (2014): Using zebrafish as a model system for studying the transgenerational effects of dioxin. Toxicol Sci 138, 403-11

Baumard P, Budzinski H, Garrigues P, Sorbe JC, Burgeot T, Bellocq J (1998): Concentrations of PAHs (polycyclic aromatic hydrocarbons) in various marine organisms in relation to those in sediments and to trophic level. Marine Pollution Bulletin 36, 951-960

Benlahcen KT, Chaoui A, Budzinski H, Bellocq J, Garrigues P (1997): Distribution and sources of polycyclic aromatic hydrocarbons in some Mediterranean coastal sediments. Marine Pollution Bulletin 34, 298-305

Billiard SM, Hahn ME, Franks DG, Peterson RE, Bols NC, Hodson PV (2002): Binding of polycyclic aromatic hydrocarbons (PAHs) to teleost aryl hydrocarbon receptors (AHRs). Comp Biochem Physiol B Biochem Mol Biol 133, 55-68

Bodiguel X, Loizeau V, Le Guellec AM, Roupsard F, Philippon X, Mellon-Duval C (2009): Influence of sex, maturity and reproduction on PCB and p,p'DDE concentrations and repartitions in the European hake (Merluccius merluccius, L.) from the Gulf of Lions (N.W. Mediterranean). Sci Total Environ 408, 304-11 
Brion F, Le Page Y, Piccini B, Cardoso O, Tong S-K, Chung B-c, Kah O (2012): Screening Estrogenic Activities of Chemicals or Mixtures In Vivo Using Transgenic (cyp19a1b-GFP) Zebrafish Embryos. PLoS ONE 7, e36069

Budzinski H, Jones I, Bellocq J, Piérard C, Garrigues P (1997): Evaluation of sediment contamination by polycyclic aromatic hydrocarbons in the Gironde estuary. Marine Chemistry 58, 85-97

Burgess HA, Granato M (2007): Modulation of locomotor activity in larval zebrafish during light adaptation. Journal of Experimental Biology 210, 2526-2539

Cachat J et al. (2010): Modeling withdrawal syndrome in zebrafish. Behav Brain Res 208, 371-6

Cachot J, Geffard O, Augagneur S, Lacroix S, Le Menach K, Peluhet L, Couteau J, Denier X, Devier MH, Pottier D, Budzinski $H$ (2006): Evidence of genotoxicity related to high PAH content of sediments in the upper part of the Seine estuary (Normandy, France). Aquatic Toxicology 79, 257-267

Cailleaud K, Forget-Leray J, Souissi S, Hilde D, LeMenach K, Budzinski H (2007): Seasonal variations of hydrophobic organic contaminant concentrations in the water-column of the Seine Estuary and their transfer to a planktonic species Eurytemora affinis (Calanoida, copepoda). Part 1: PCBs and PAHs. Chemosphere 70, 270-280

Corrales J, Fang X, Thornton C, Mei W, Barbazuk WB, Duke M, Scheffler BE, Willett KL (2014): Effects on specific promoter DNA methylation in zebrafish embryos and larvae following benzo[a]pyrene exposure. Comp Biochem Physiol C Toxicol Pharmacol 163, 37-46

Correia AD, GonÃßalves R, Scholze M, Ferreira M, Henriques MA-R (2007): Biochemical and behavioral responses in gilthead seabream (Sparus aurata) to phenanthrene. Journal of Experimental Marine Biology and Ecology 347, 109-122

Crépeaux G, Bouillaud-Kremarik P, Sikhayeva N, Rychen G, Soulimani R, Schroeder H (2012): Late effects of a perinatal exposure to a 16 PAH mixture: Increase of anxiety-related behaviours and decrease of regional brain metabolism in adult male rats. Toxicology Letters 211, 105113

Crépeaux G, Bouillaud-Kremarik P, Sikhayeva N, Rychen G, Soulimani R, Schroeder H (2013): Exclusive prenatal exposure to a 16 PAH mixture does not impact anxiety-related behaviours and regional brain metabolism in adult male rats: A role for the period of exposure in the modulation of PAH neurotoxicity. Toxicology Letters 221, 40-46

Daouk T, Larcher T, Roupsard F, Lyphout L, Rigaud C, Ledevin M, Loizeau V, Cousin X (2011): Longterm food-exposure of zebrafish to PCB mixtures mimicking some environmental situations induces ovary pathology and impairs reproduction ability. Aquat Toxicol 105, 270-8

Edwards SC, Jedrychowski W, Butscher M, Camann D, Kieltyka A, Mroz E, Flak E, Li Z, Wang S, Rauh V, Perera $F(2010)$ : Prenatal exposure to airborne polycyclic aromatic hydrocarbons and children's intelligence at 5 years of age in a prospective cohort study in Poland. Environ Health Perspect 118, 1326-31

Egan RJ, Bergner CL, Hart PC, Cachat JM, Canavello PR, Elegante MF, Elkhayat SI, Bartels BK, Tien AK, Tien DH, Mohnot S, Beeson E, Glasgow E, Amri H, Zukowska Z, Kalueff AV (2009): Understanding behavioral and physiological phenotypes of stress and anxiety in zebrafish. Behav Brain Res 205, 38-44

Eisler R (1987): Polycylic Aromatic Hydrocarbons Hazards to Fish, Wildlife, and Invertebrates: A Synoptic Review. U.S. Fish and Wildlife Service, Washington, DC. Biological Report 85, 1-11

Emran F, Rihel J, Dowling JE (2008): A behavioral assay to measure responsiveness of zebrafish to changes in light intensities. Journal of visualized experiments : JoVE, e293

Fang X, Thornton C, Scheffler BE, Willett KL (2013): Benzo[a]pyrene decreases global and gene specific DNA methylation during zebrafish development. Environ Toxicol Pharmacol 36, 40-50

Goncalves R, Scholze M, Ferreira AM, Martins M, Correia AD (2008): The joint effect of polycyclic aromatic hydrocarbons on fish behavior. Environmental Research 108, 205-213

Gravato C, Guilhermino L (2009): Effects of Benzo(a)pyrene on Seabass (Dicentrarchus labrax L.): Biomarkers, Growth and Behavior. Human and Ecological Risk Assessment: An International Journal 15, 121-137 
He J, Yang D, Wang C, Liu W, Liao J, Xu T, Bai C, Chen J, Lin K, Huang C, Dong Q (2011): Chronic zebrafish low dose decabrominated diphenyl ether (BDE-209) exposure affected parental gonad development and locomotion in F1 offspring. Ecotoxicology 20, 1813-22

Jeanneret H, Chantereau S, Belliaeff B, Ratiskol G, Allenou J-P, Piclet G (2002): Suivi sanitaire et environnemental des conséquences de la marée noire de l'Erika. In: Cedre (Hrsg.), Colloque SAFERSEAS: les leçons techniques de l'Erika et des autres accidents, Brest

Jedrychowski W, Whyatt RM, Camann DE, Bawle UV, Peki K, Spengler JD, Dumyahn TS, Penar A, Perera FF (2003): Effect of prenatal PAH exposure on birth outcomes and neurocognitive development in a cohort of newborns in Poland. Study design and preliminary ambient data. Int J Occup Med Environ Health 16, 21-9

Johnson LL, Ylitalo GM, Arkoosh MR, Kagley AN, Stafford C, Bolton JL, Buzitis J, Anulacion BF, Collier TK (2007): Contaminant exposure in outmigrant juvenile salmon from Pacific Northwest estuaries of the United States. Environmental Monitoring and Assessment 124, 167-194

Lange A, Paull GC, Coe TS, Katsu Y, Urushitani H, Iguchi T, Tyler CR (2009): Sexual Reprogramming and Estrogenic Sensitization in Wild Fish Exposed to Ethinylestradiol. Environmental Science \& Technology 43, 1219-1225

Larcher T, Perrichon P, Vignet C, Ledevin M, Le Menach K, Lyphout L, Landi L, Clerandeau C, Lebihanic F, Menard D, Burgeot T, Budzinski H, Akcha F, Cachot J, Cousin X (2014): Chronic dietary exposure of zebrafish to PAH mixtures results in carcinogenic but not genotoxic effects. Environ Sci Pollut Res Int

Latimer JS, Zheng J (2003): The Sources, Transport, and Fate of PAHs in the Marine Environment, PAHs: An Ecotoxicological Perspective. John Wiley \& Sons, Ltd, pp. 7-33

Le Bihanic F, Clerandeau C, Le Menach K, Morin B, Budzinski H, Cousin X, Cachot J (2014a): Developmental toxicity of PAH mixtures in fish early life stages. Part II: adverse effects in Japanese medaka. Environ Sci Pollut Res Int

Le Bihanic F, Morin B, Cousin X, Le Menach K, Budzinski H, Cachot J (2014b): Developmental toxicity of PAH mixtures in fish early life stages. Part I: adverse effects in rainbow trout. Environ Sci Pollut Res Int

Le Goff J, Gallois J, Pelhuet L, Devier MH, Budzinski H, Pottier D, André V, Cachot J (2006): DNA adduct measurements in zebra mussels, Dreissena polymorpha, Pallas: Potential use for genotoxicant biomonitoring of fresh water ecosystems. Aquatic Toxicology 79, 55-64

Letcher RJ, Bustnes JO, Dietz R, Jenssen BM, Jørgensen EH, Sonne C, Verreault J, Vijayan MM, Gabrielsen GW (2010): Exposure and effects assessment of persistent organohalogen contaminants in arctic wildlife and fish. Science of The Total Environment 408, 2995-3043

Levin ED, Bencan Z, Cerutti DT (2007): Anxiolytic effects of nicotine in zebrafish. Physiol Behav 90, 548

Lucas J, Perrichon P, Nouhaud M, Audras A, Leguen I, Lefrancois C (2014): Aerobic metabolism and cardiac activity in the descendants of zebrafish exposed to pyrolytic polycyclic aromatic hydrocarbons. Environ Sci Pollut Res Int

MacPhail RC, Brooks J, Hunter DL, Padnos B, Irons TD, Padilla S (2009): Locomotion in larval zebrafish: Influence of time of day, lighting and ethanol. NeuroToxicology 30, 52-58

Mattingly CJ, Toscano WA (2001): Posttranscriptional silencing of cytochrome P4501A1 (CYP1A1) during zebrafish (Danio rerio) development. Developmental Dynamics 222, 645-654

McCormick SD, Shrimpton JM, Carey JB, O'Dea MF, Sloan KE, Moriyama S, Björnsson BT (1998): Repeated acute stress reduces growth rate of Atlantic salmon parr and alters plasma levels of growth hormone, insulin-like growth factor I and cortisol. Aquaculture 168, 221-235

Mirbahai L, Williams TD, Zhan H, Gong Z, Chipman JK (2011): Comprehensive profiling of zebrafish hepatic proximal promoter $\mathrm{CpG}$ island methylation and its modification during chemical carcinogenesis. BMC genomics 12, 3

Monteverdi GH, Giulio RTD (2000): In vitro and in vivo association of 2,3,7,8-tetrachlorodibenzo-pdioxin and benzo[a]pyrene with the yolk-precursor protein vitellogenin. Environmental Toxicology and Chemistry 19, 2502-2511 
Neff JM (1979): Polycyclic aromatic hydrocarbons in the aquatic environment sources, fates, and biological effects. Applied Science Publishers, London

Nüsslein-Volhard C, Dahm R (2002): Zebrafish: a pratical approach. The Pratical Approach Series, Oxford University Press 261, 8-37

Oliveira M, Gravato C, Guilhermino L (2012): Acute toxic effects of pyrene on Pomatoschistus microps (Teleostei, Gobiidae): Mortality, biomarkers and swimming performance. Ecological Indicators 19, 206-214

Ottinger MA, Lavoie ET, Abdelnabi M, Quinn MJ, Jr., Marcell A, Dean K (2009): An overview of dioxinlike compounds, $\mathrm{PCB}$, and pesticide exposures associated with sexual differentiation of neuroendocrine systems, fluctuating asymmetry, and behavioral effects in birds. J Environ Sci Health C Environ Carcinog Ecotoxicol Rev 27, 286-300

Ottinger MA, Carro T, Bohannon M, Baltos Lf, Marcell AM, McKernan M, Dean KM, Lavoie E, Abdelnabi $M$ (2013): Assessing effects of environmental chemicals on neuroendocrine systems: potential mechanisms and functional outcomes. Gen Comp Endocrinol 190, 194-202

Palanza P, Gioiosa L, vom Saal FS, Parmigiani S (2008): Effects of developmental exposure to bisphenol A on brain and behavior in mice. Environ Res 108, 150-7

Panzica GC, Viglietti-Panzica C, Mura E, Quinn MJ, Jr., Lavoie E, Palanza P, Ottinger MA (2007): Effects of xenoestrogens on the differentiation of behaviorally-relevant neural circuits. Front Neuroendocrinol 28, 179-200

Payne JR, Driskell WB, Short JW, Larsen ML (2008): Long term monitoring for oil in the Exxon Valdez spill region. Mar Pollut Bull 56, 2067-81

Pean S, Daouk T, Vignet C, Lyphout L, Leguay D, Loizeau V, Begout ML, Cousin X (2013): Long-term dietary-exposure to non-coplanar PCBs induces behavioral disruptions in adult zebrafish and their offspring. Neurotoxicol Teratol 39, 45-56

Pelletier MC, Burgess RM, Cantwell MG, Serbst JR, Ho KT, Ryba SA (2000): Importance of maternal transfer of the photoreactive polycyclic aromatic hydrocarbon fluoranthene from benthic adult bivalves to their pelagic larvae. Environmental Toxicology and Chemistry 19, 2691-2698

Pereira MG, Walker LA, Wright J, Best J, Shore RF (2009): Concentrations of polycyclic aromatic hydrocarbons (PAHs) in the eggs of predatory birds in Britain. Environ Sci Technol 43, 9010-5

Perera FP, Tang D, Wang S, Vishnevetsky J, Zhang B, Diaz D, Camann D, Rauh V (2012): Prenatal polycyclic aromatic hydrocarbon (PAH) exposure and child behavior at age 6-7 years. Environ Health Perspect 120, 921-6

Perrichon P 2014: Développement de tests embryo-larvaires prédictifs d'effets toxiques précoces et tardifs pour des molécules hydrophobe, La Rochelle, $300 \mathrm{pp}$

Reyhanian N, Volkova K, Hallgren S, Bollner T, Olsson PE, Olsen H, Hallstrom IP (2011): 17alphaEthinyl estradiol affects anxiety and shoaling behavior in adult male zebra fish (Danio rerio). Aquat Toxicol 105, 41-8

Sackerman J, Donegan JJ, Cunningham CS, Nguyen NN, Lawless K, Long A, Benno RH, Gould GG (2010): Zebrafish behavior in novel environments: effects of acute exposure to anxiolytic compounds and choice of Danio rerio line. Int J Comp Psychol 23, 43-61

Sagiv SK, Thurston SW, Bellinger DC, Tolbert PE, Altshul LM, Korrick SA (2010): Prenatal organochlorine exposure and behaviors associated with attention deficit hyperactivity disorder in school-aged children. Am J Epidemiol 171, 593-601

Schnorr SJ, Steenbergen PJ, Richardson MK, Champagne DL (2012): Measuring thigmotaxis in larval zebrafish. Behaviour Brain Research 228, 367-374

Scott GR, Sloman KA (2004): The effects of environmental pollutants on complex fish behaviour: integrating behavioural and physiological indicators of toxicity. Aquatic Toxicology 68, 369392

Shen H, Huang Y, Wang R, Zhu D, Li W, Shen G, Wang B, Zhang Y, Chen Y, Lu Y, Chen H, Li T, Sun K, Li B, Liu W, Liu J, Tao S (2013): Global atmospheric emissions of polycyclic aromatic hydrocarbons from 1960 to 2008 and future predictions. Environmental science \& technology 47, 6415-6424 
Steenbergen PJ, Richardson MK, Champagne DL (2011): The use of the zebrafish model in stress research. Prog Neuropsychopharmacol Biol Psychiatry 35, 1432-51

Stewart P, Reihman J, Lonky E, Darvill T, Pagano J (2000): Prenatal PCB exposure and neonatal behavioral assessment scale (NBAS) performance. Neurotoxicology and Teratology 22, 21-29

Stocco C (2012): Tissue physiology and pathology of aromatase. Steroids 77, 27-35

Tang D, Li TY, Liu JJ, Zhou ZJ, Yuan T, Chen YH, Rauh VA, Xie J, Perera F (2008): Effects of prenatal exposure to coal-burning pollutants on children's development in China. Environ Health Perspect 116, 674-9

Tilghman Hall A, Oris JT (1991): Anthracene reduces reproductive potential is maternally transferred during long-term exposure in fathead minnows. Aquatic Toxicology 19, 249-264

Tong SK, Mouriec K, Kuo MW, Pellegrini E, Gueguen MM, Brion F, Kah O, Chung BC (2009): A cyp19a1b-gfp (aromatase B) transgenic zebrafish line that expresses GFP in radial glial cells. Genesis 47, 67-73

Varanasi U, Casillas E, Arkoosh MR, Hom T, Misitano D, Brown DW, Chan S-L, Collier TK, McCain BB, Stein JE 1993: Contaminant exposure and associated biological effects in juvenile Chinook salmon (Oncorhynchus tshawytscha) from urban and nonurban estuaries of Puget Sound, WA NOAA Fisheries

Vignet C, Bégout M-L, Péan S, Lyphout L, Leguay D, Cousin X (2013): Systematic screening of behavioral responses in two zebrafish strains. Zebrafish 10, 365-75

Vignet C 2014: Altération de la physiologie des poissons exposés à des hydrocarbures aromatiques polycycliques (HAP) Comportement et reproduction, La Rochelle, $350 \mathrm{pp}$

Vignet C, Devier MH, Le Menach K, Lyphout L, Potier J, Cachot J, Budzinski H, Begout ML, Cousin X (2014a): Long-term disruption of growth, reproduction, and behavior after embryonic exposure of zebrafish to PAH-spiked sediment. Environ Sci Pollut Res Int

Vignet C, Le Menach K, Lyphout L, Guionnet T, Frere L, Leguay D, Budzinski H, Cousin X, Begout ML (2014b): Chronic dietary exposure to pyrolytic and petrogenic mixtures of PAHs causes physiological disruption in zebrafish-part II: behavior. Environ Sci Pollut Res Int

Vignet C, Le Menach K, Mazurais D, Lucas J, Perrichon P, Le Bihanic F, Devier MH, Lyphout L, Frere L, Begout ML, Zambonino-Infante JL, Budzinski H, Cousin X (2014c): Chronic dietary exposure to pyrolytic and petrogenic mixtures of PAHs causes physiological disruption in zebrafish - part I: Survival and growth. Environ Sci Pollut Res Int

Volkova K, Reyhanian N, Kot-Wasik A, Olsen H, Porsch-Hallstrom I, Hallgren S (2012): Brain circuit imprints of developmental 17alpha-Ethinylestradiol exposure in guppies (Poecilia reticulata): persistent effects on anxiety but not on reproductive behaviour. Gen Comp Endocrinol 178, 282-90

Wormley DD, Ramesh A, Hood DB (2004): Environmental contaminant-mixture effects on CNS development, plasticity, and behavior. Toxicology and Applied Pharmacology 197, 49-65

Yanagida GK, Anulacion BF, Bolton JL, Boyd D, Lomax DP, Paul Olson O, Sol SY, Willis M, Ylitalo GM, Johnson LL (2012): Polycyclic aromatic hydrocarbons and risk to threatened and endangered Chinook salmon in the Lower Columbia River estuary. Archives of Environmental Contamination and Toxicology 62, 282-295

Yunker MB, Macdonald RW, Vingarzan R, Mitchell RH, Goyette D, Sylvestre S (2002): PAHs in the Fraser River basin: a critical appraisal of PAH ratios as indicators of PAH source and composition. Organic Geochemistry 33, 489-515

Zhang Y, Tao S (2009): Global atmospheric emission inventory of polycyclic aromatic hydrocarbons (PAHs) for 2004. Atmospheric Environment 43, 812-819 


\section{Figure captions}

Fig. 1 Photomotor response of $5 \mathrm{dpf}$ offspring larvae. Distance travelled per 5-min periods before, during and after a light off period for larvae issued from PY ( $a$ in details, $b$ averaged per 5-min periods), larvae issued from HO (c in details, d averaged per 5-min periods) and larvae issued from LO (e in details, $\mathrm{f}$ averaged per 5-min periods). Values are mean \pm SEM; $\mathrm{n}=82$ Control (from $\mathrm{N}=8$ spawns), $\mathrm{n}=510.3 \mathrm{X}(\mathrm{N}=5), \mathrm{n}=681 \mathrm{X}(\mathrm{N}=5)$ and $\mathrm{n}=603 \mathrm{X}(\mathrm{N}=1)$ for larvae issued from PY fish; $n=121(\mathrm{~N}=3)$ Control and $\mathrm{n}=97(\mathrm{~N}=3)$ 0.3X for larvae issued from HO fish; $n=61(\mathrm{~N}=3)$ Control and $\mathrm{n}=61(\mathrm{~N}=3)$ 0.3X for larvae issued from LO fraction; letters indicate significant difference at $\mathrm{p}<0.05$ between concentrations within 5 -min periods.

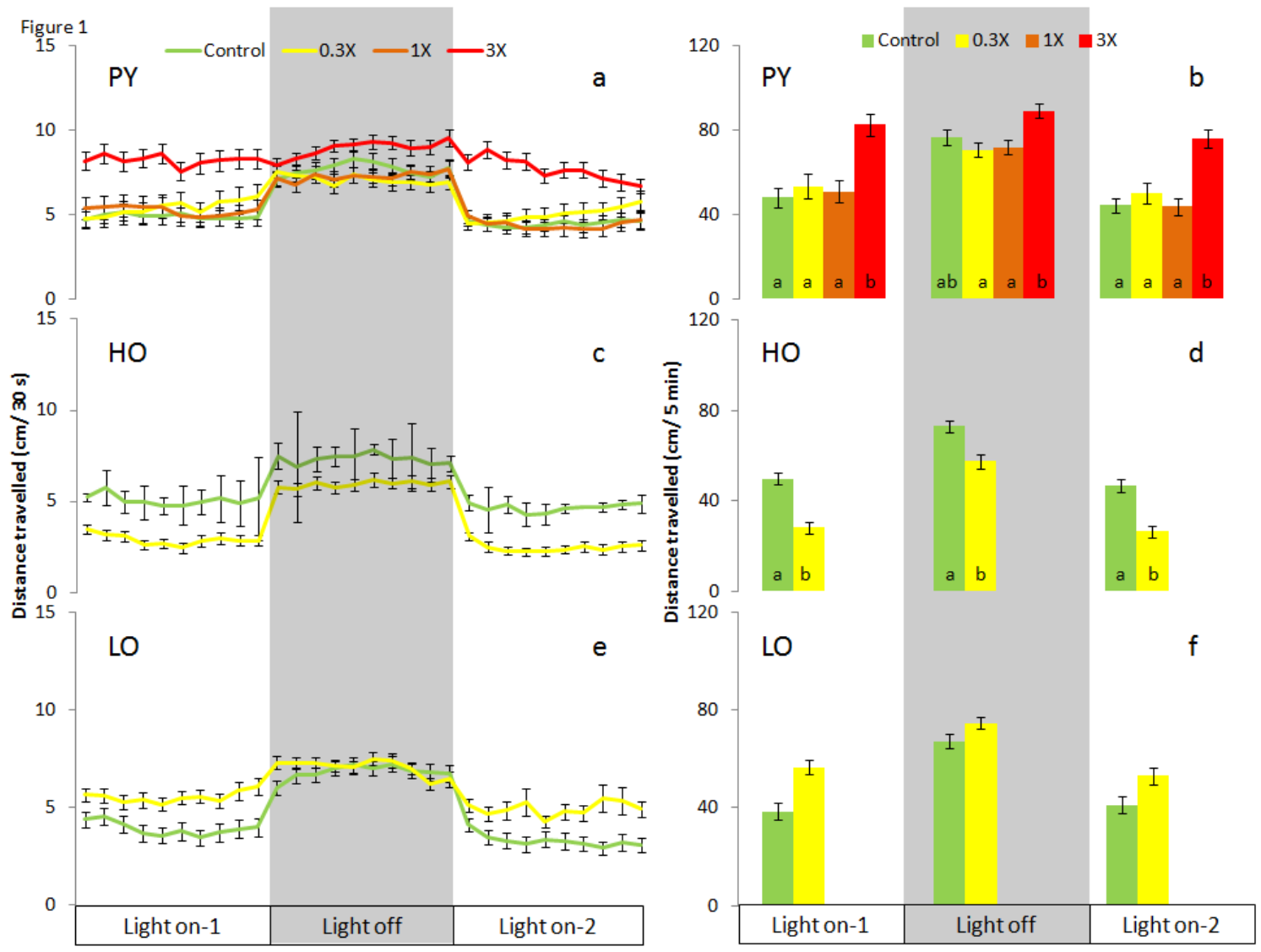


Fig. 2 Seventy-two-hour swimming activity setup in F1 larvae. Evolution of distance travelled (cm/30min) for PY larvae in relation to time, values are means without SEM for graph readability (a); Averaged distance travelled for day and night periods, values are mean \pm SEM for larvae issued from PY (b) and for larvae issued from LO (c); $\mathrm{n}=27$ (N=4 spawns) Control, $21(\mathrm{~N}=4)$ 0.3X, $20(\mathrm{~N}=4) 1 \mathrm{X}$ and $15(\mathrm{~N}=1) 3 \mathrm{X}$ for larvae issued from PY ; $\mathrm{n}=23(\mathrm{~N}=2)$ Control, $n=24(\mathrm{~N}=1) 0.3 \mathrm{X}$ and $\mathrm{n}=23(\mathrm{~N}=2)$ 1X for larvae issued from LO; letters indicate significant difference at $\mathrm{p}<0.05$ between concentrations within day periods.

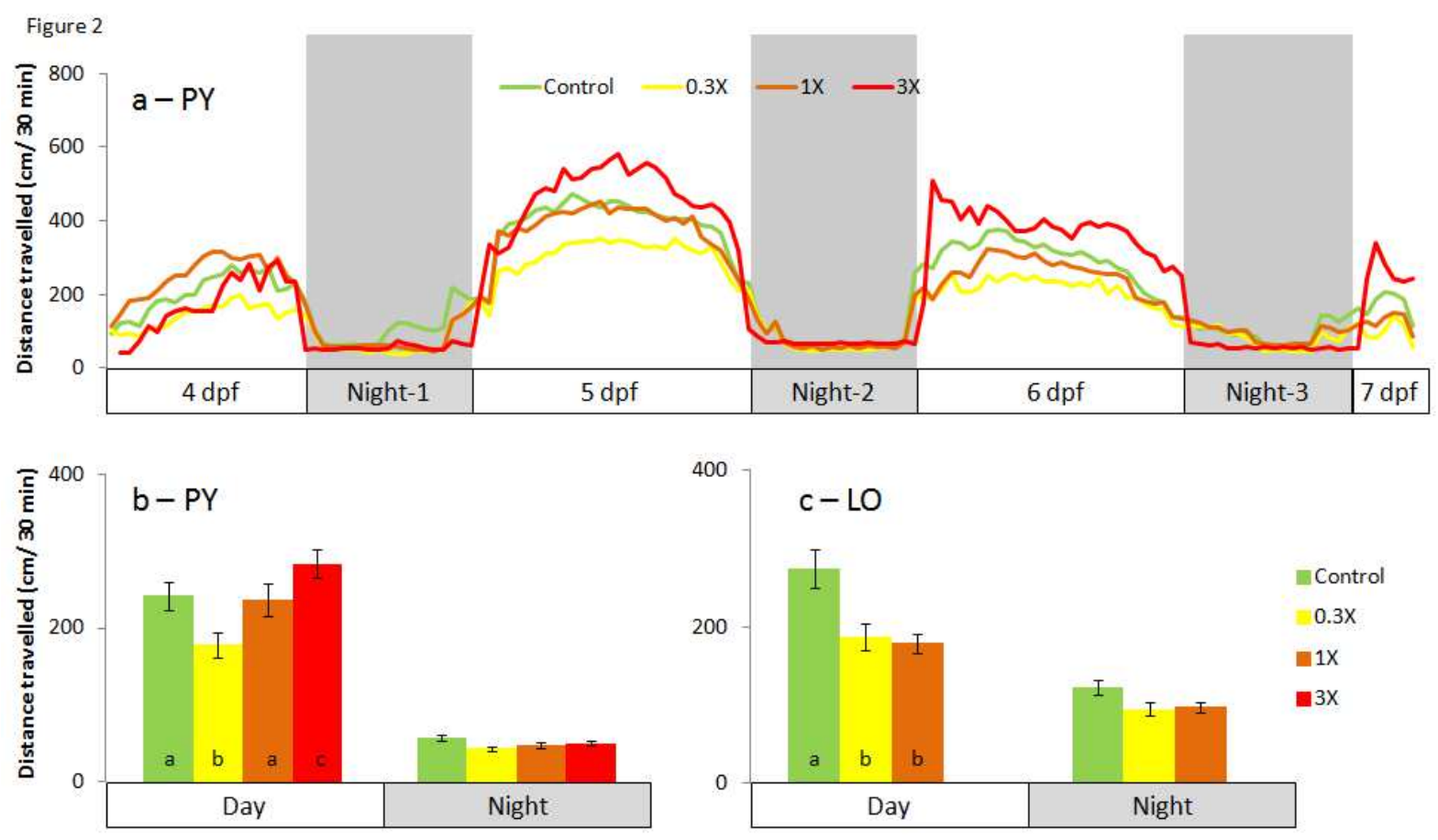


Fig. 3 Novel tank challenge in 2 month-old juveniles issued from PY fish. Mean time spent (s) per minute (Min-1 to Min-6) in the top area of the novel tank (a) is different between concentrations $(\mathrm{F}=5.39 ; \mathrm{p}=0.001)$ with $3 \mathrm{X}$ being different from Control $(\mathrm{p}=0.008)$. Total distance travelled $(\mathrm{cm})$ over the 6-min challenge (b) and total time spent immobile (s) over the 6-min challenge $(\mathrm{c})$. Values are mean $\pm \mathrm{SEM} ; \mathrm{n}=74$ control, $\mathrm{n}=550.3 \mathrm{X}, \mathrm{n}=84 \mathrm{X}$ and $\mathrm{n}=75$ $3 \mathrm{X}$ for larvae issued from $\mathrm{PY}$ fish ( $\mathrm{N}=2$ spawns).

Figure 3
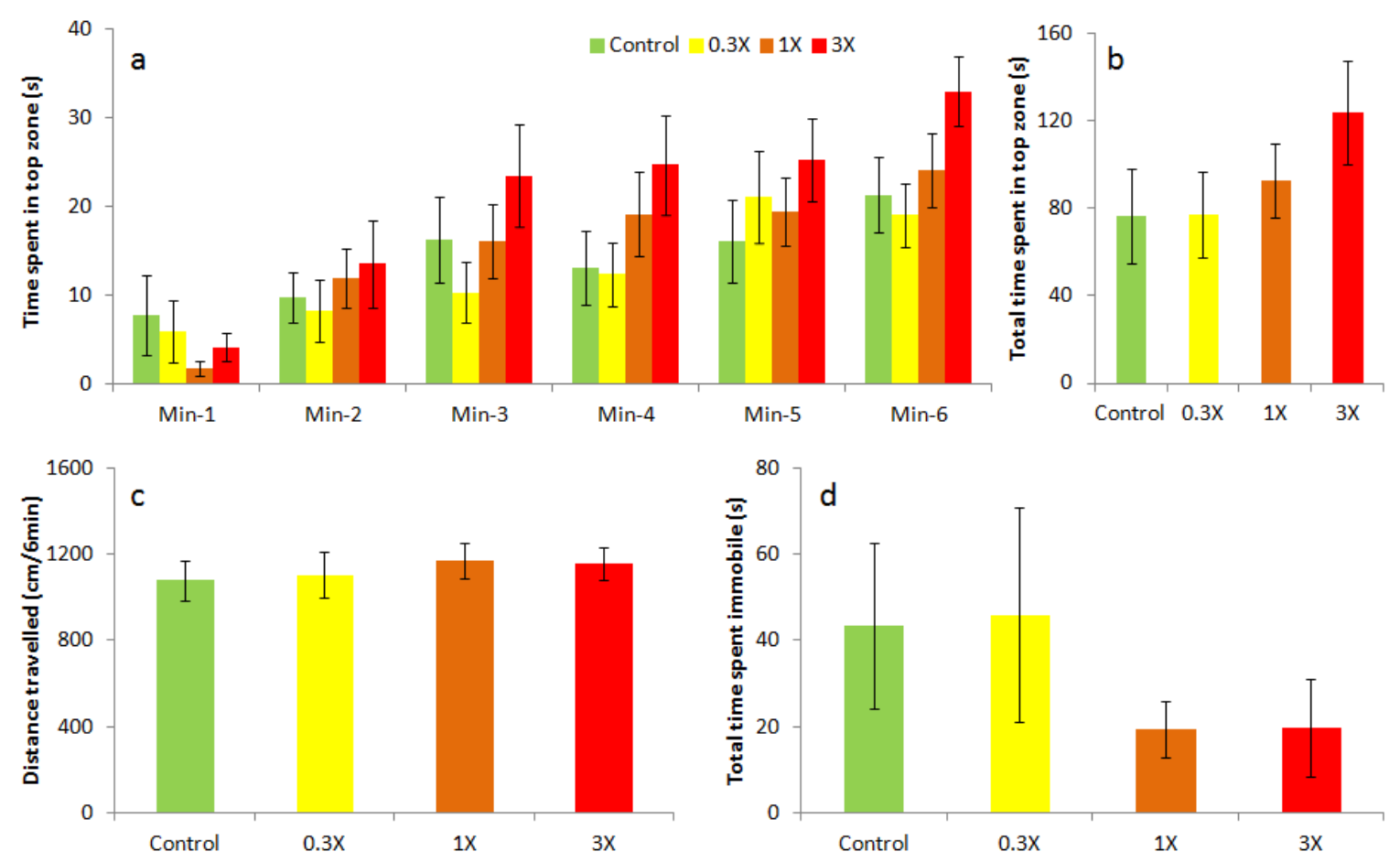
Fig. 4 Photomotor response of F2-PY 5 dpf larvae issued from F1-PY. Distance travelled per 5-min periods before, during and after a light off period ( $\mathrm{a}$ in details, $\mathrm{b}$ averaged per 5-min periods). Values are mean $\pm \mathrm{SEM} ; \mathrm{n}=82(\mathrm{~N}=4$ spawns) Control, $\mathrm{n}=51(\mathrm{~N}=3) 0.3 \mathrm{X}, \mathrm{n}=68$ $(\mathrm{N}=3) 1 \mathrm{X}$ and $\mathrm{n}=60(\mathrm{~N}=3) 3 \mathrm{X}$ for larvae issued from F1-PY fish; letters indicate significant difference at $\mathrm{p}<0.05$ between concentrations within 5-min periods.

Figure 4

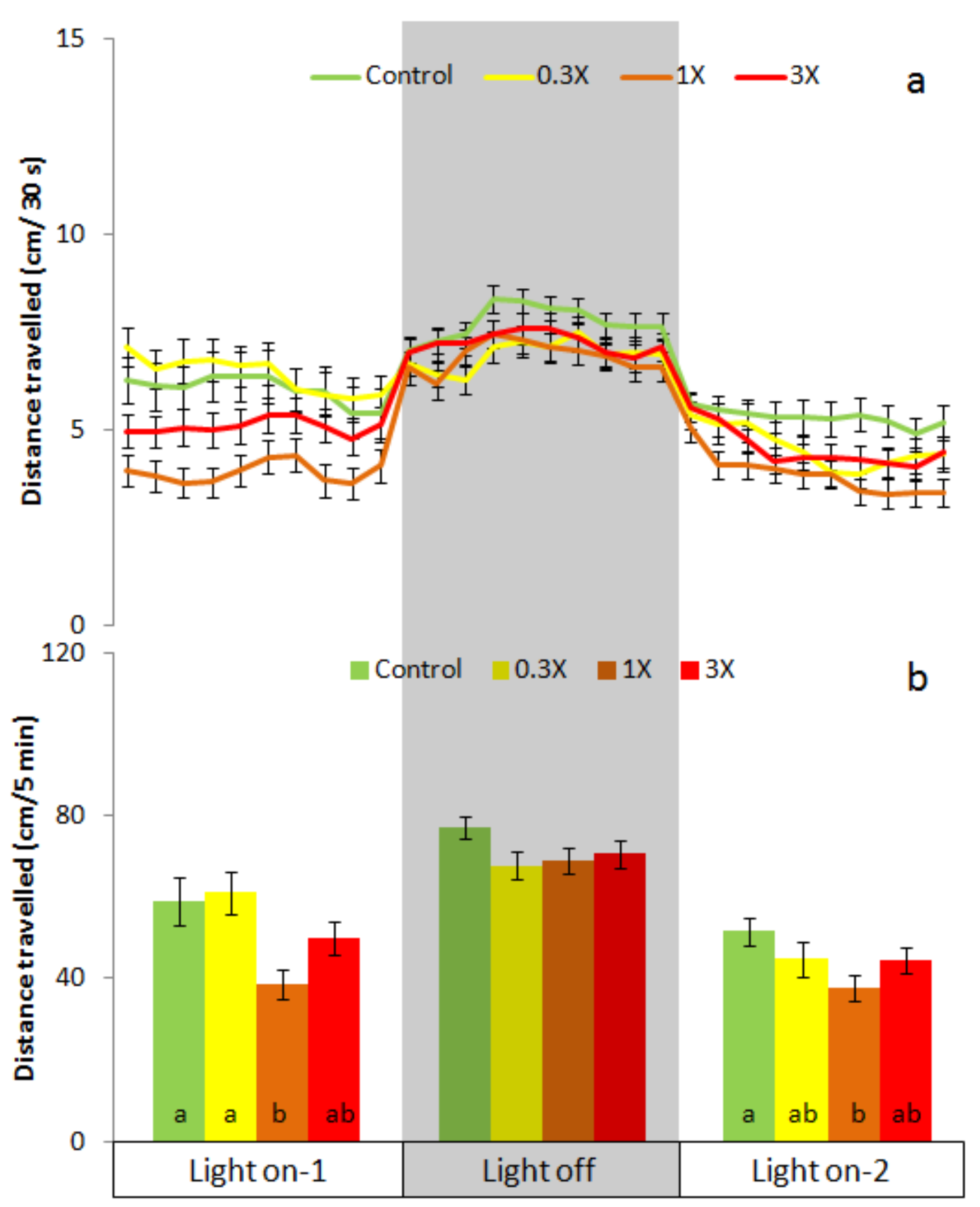


Fig. 5 Brain aromatase expression in number of fluorescent pixels extracted from images of the head region of larvae issued from $t g$ cyp19alb exposed through diets to PY fish (a), HO (b) and LO (c) fractions in relation to EE2 concentration (nM). Letters indicate significant difference at $\mathrm{p}<0.05$ between concentrations to which parents were exposed within each EE2 concentrations, detailed number of picture taken per fraction and concentration is given in supplementary table 1.

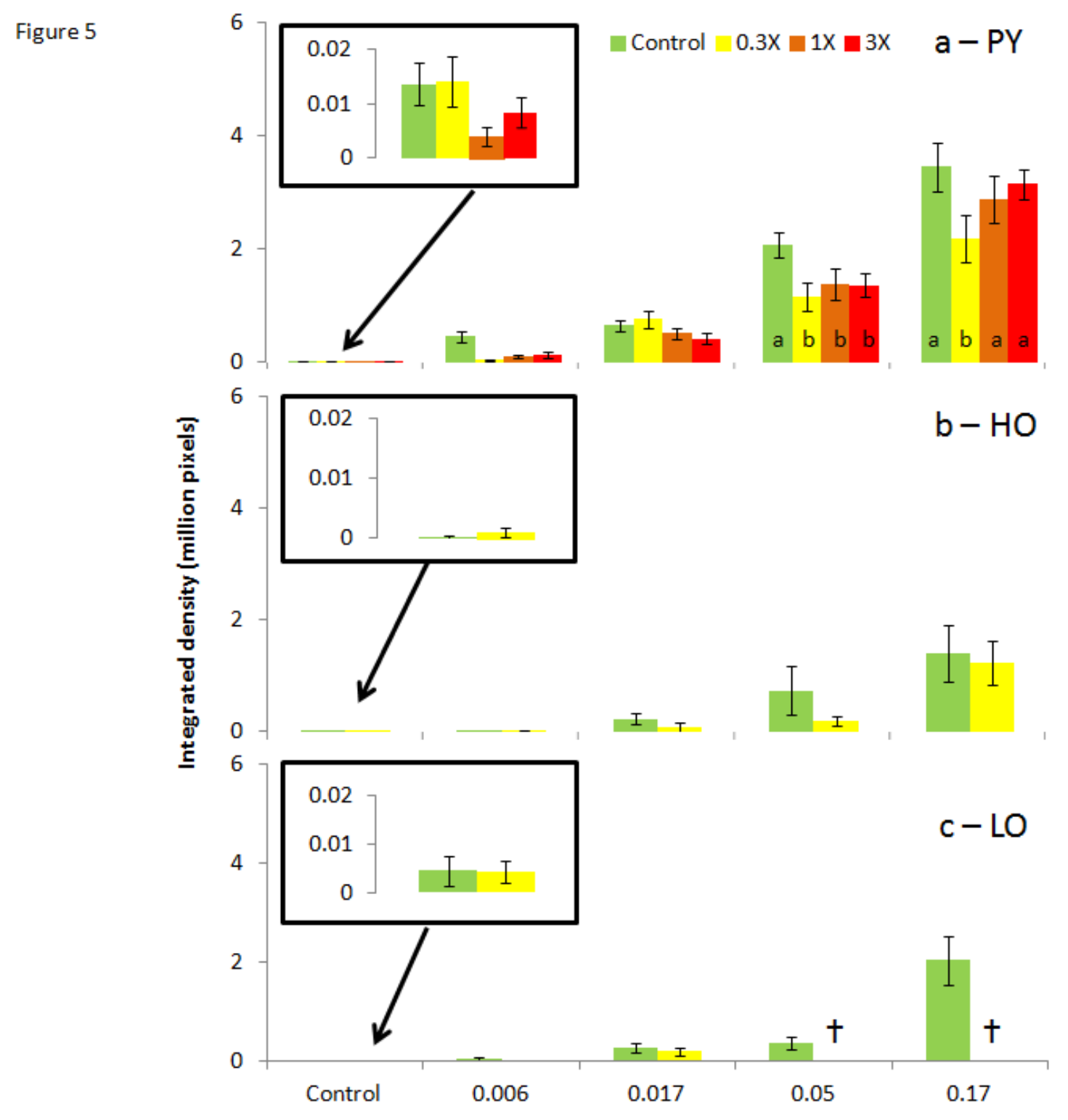


Supplementary Table 1: Number of larvae photographed per fraction and concentration ( $\mathrm{N}=2-4$ spawns).

\begin{tabular}{ccccccc}
\hline & & Control & $\mathbf{0 . 0 0 6} \mathbf{n M}$ & $\mathbf{0 . 0 1 7} \mathbf{~ M M}$ & $\mathbf{0 . 0 5} \mathbf{n M}$ & $\mathbf{0 . 1 7} \mathbf{n M}$ \\
\hline \multirow{3}{*}{ PY } & Control & 87 & 72 & 73 & 94 & 58 \\
& $0.3 \mathrm{X}$ & 61 & 26 & 49 & 23 & 26 \\
& $1 \mathrm{X}$ & 59 & 69 & 67 & 56 & 41 \\
& $3 \mathrm{X}$ & 88 & 58 & 65 & 49 & 72 \\
\hline \multirow{2}{*}{ HO } & Control & 20 & 19 & 20 & 14 & 19 \\
& $0.3 \mathrm{X}$ & 18 & 15 & 9 & 13 & 22 \\
\hline \multirow{2}{*}{ LO } & Control & 21 & 17 & 22 & 14 & 16 \\
& $0.3 \mathrm{X}$ & 22 & 14 & 25 & 0 & 0 \\
\hline
\end{tabular}

